\title{
ANÁLISE TENSIVA DAS RELAÇÕES ENTRE IMAGENS E LEGENDAS EM ASTROFÍSICA
}

\section{TENSIVE ANALISIS OF THE IMAGES/CAPTIONS RELATIONS IN ASTROPHYSICS}

\author{
Lionel Sturnack ${ }^{1}$ \\ USP - Universidade de São Paulo \\ ULg - Université de Liège \\ WBI - Wallonie-Bruxelles International
}

\begin{abstract}
RESUMO: A descrição semiótica que proporemos, neste trabalho, incide sobre três tipos de textos de legenda que pertencem ao discurso científico lato sensu da área astrofísica. O propósito é analisá-las com as ferramentas propostas pela semiótica tensiva, desenvolvida por Claude Zilberberg e Jacques Fontanille, a fim de estabelecer os critérios tensivos sobre os quais poderíamos efetuar uma diferenciação genérica entre estes discursos.
\end{abstract}

PALAVRAS-CHAVE: Imagem; legenda; astrofísica; semiótica tensiva.

ABSTRACT: We propose in this work doing a semiotic description with three types of captions that belong to the scientific speech of astrophysical field. The purpose is to develop the analysis with the tools proposed by tensive semiotics, developed by Claude Zilberberg and Jacques Fontanille, in order to establish the background in which we could make a generic differentiation of these speeches.

KEYWORDS: Image; caption; astrophysics; tensive semiotics.

A descrição que proporemos, neste trabalho, incide sobre três tipos de textos que pertencem ao discurso científico lato sensu da área da astrofísica: o discurso da ciência em laboratório, da ciência em artigos especializados e da ciência em artigos de vulgarização. O propósito é analisar os três discursos com as ferramentas propostas pela semiótica tensiva, desenvolvida por Claude Zilberberg e Jacques Fontanille. O objetivo corresponde a estabelecer os critérios tensivos sobre os quais poderíamos efetuar uma diferenciação genérica entre os discursos analisados. Outro objetivo, que seria mais lateral, será também reconhecer algumas perguntas específicas que propõe o objeto à semiótica tensiva. Pretendemos, então, desembocar em uma sistematização das diferenças entre esses discursos, que iria além das

\footnotetext{
${ }^{1}$ Doutorando da USP - Universidade de São Paulo, ULg - Université de Liège, WBI - Wallonie - Bruxelas Internacional. 
considerações argumentativas ou figurativas e sustentaria, por conseguinte, os mais recentes desenvolvimentos da semiótica aplicada à imagem científica.

\section{Introdução}

O corpus com o qual trabalharemos se compõe de três tipos de discursos diferenciados pelos critérios da recepção e das etapas da pesquisa científica a respeito de um objeto. A primeira diferença separa discursos especializados e de vulgarização; por isso, temos, de um lado, artigos de revista universitária e discursos orais de centros de pesquisas e, de outro, artigos da Scientific American Brasil. A segunda opera a separação entre ciência feita e aquela sendo feita no nível especializado, ou seja, os artigos publicados em Astronomy \& Astrophysics e os discursos de laboratório do Center for Astrophysics (CfA) de Harvard. Esta última fonte foi gravada e transcrita por Catherine Allamel-Raffin na sua tese de doutorado sobre a produção e as funções das imagens em física dos materiais e em astrofísica (ALLAMEL-RAFFIN, 2004). ${ }^{2}$ Entre os três discursos, trata-se de uma distinção a priori, baseada no lugar de enunciação e no tipo de recepção. Uma análise mais profunda das estruturas tensivas de cada um levaria em consideração os tipos de apresentação e de dinamismo dos conteúdos, oferecendo uma base estável de diferenciação. Por isso, usaremos quatro conceitos fundamentais da semiótica tensiva: os modos de presença, de efíciência, de junção e a fidúcia. Um quinto conceito poderia ser utilizado, trata-se dos modos de existência, isto é, o foco e a apreensão. ${ }^{3}$ Esses ajudarão a apresentação dos resultados, mas não faremos deles um uso sistemático.

Antes de entrar nas análises, é preciso delinear o âmbito semiótico no qual se coloca a nossa pesquisa, o que permite dar alguma substância ao trabalho. Por isso, é preciso retomar as linhas importantes de um recente artigo de Maria Giulia Dondero, chamado "Sémiotique de l'image scientifique" (DONDERO, 2010), no qual a autora apresenta as tendências das pesquisas semióticas a respeito da imagem nas ciências e oferece um condensado das questões que as orientam. A primeira seção do artigo é dedicada às práticas de instanciação, nas quais a autora reconhece três etapas que estruturam as pesquisas científicas em geral: interrogação, estabilização e institucionalização (DONDERO, 2010, p. 118-128). Apoiando-se em Bordron e Latour, ela explica que essas três práticas correspondem às etapas da busca cognitiva, que podem se distribuir segundo a tipologia peirceana dos signos, ou seja, indicialidade, iconicidade e simbolicidade, entendidos, porém, num sentido particular. Certamente o sentido peirceano estrito não dá conta do estatuto particular dos signos que compõem as imagens nas ciências, como, por exemplo, na astrofísica. ${ }^{4}$ Por isso, é preciso entender indicialidade, iconicidade e simbolicidade da maneira como Bordron as define.

Assim, poderíamos retomar as definições para ver como podem estruturar o nosso corpus como material específico no fluxo da pesquisa. Nessa perspectiva, a

\footnotetext{
${ }^{2}$ Os três discursos pertencem à mesma vontade de conseguir descrever as imagens segundo várias modalidades. Por isso, embora o discurso de laboratório pareça ser distinto dos outros, ele participa do mesmo movimento, mais amplo nesse caso, já que corresponde à primeira tentativa de interpretação das imagens. Os outros discursos de legenda, no sentido restrito, estão num estágio posterior, no qual as formas estão estabilizadas.

${ }^{3}$ Para uma distinção entre modo de existência enquanto manifestação de uma unidade no campo de presença e enquanto "consequências subjetais da autoridade do modo de eficiência", referir-se à décima quarta nota de rodapé.

${ }^{4}$ A noção de objeto que entra na estrutura triádica de Peirce não tem lugar na descrição das imagens astrofísicas, ou pelo menos não tem o lugar previsto pela estrutura peirceiana.
} 
indicialidade corresponde "aos vestígios de fenômenos, ou seja, os dados recolhidos [cujo entendimento] inclui a matéria teórica dos resultados obtidos anteriormente" (DONDERO, 2010, p. 121 - tradução nossa ${ }^{5}$ ). Na realidade, a matéria teórica é formada pelas etapas seguintes do fluxo da pesquisa, ou seja, a iconização e a simbolização.

É preciso entender a iconização como "os numerosos momentos dos tests que visam negociar e estabilizar as formas visuais mais ou menos definitivas de um objeto científico" (DONDERO, 2010, p. 121 - T.N.). Essa definição sai da concepção tradicional do iconismo já que não pressupõe um objeto exterior com o qual o signo está numa relação de semelhança, mas se trata de uma estabilização de formas e de constituição provisória de um objeto. Por fim, a simbolização caracteriza "o momento da aceitação, verificação e institucionalização destas premissas, que tinham antes o estatuto de índices, e anteriormente de teoria estabilizada" (DONDERO, 2010, p. 121, T.N.). Entende-se, então, como essa perspectiva dá conta do processo da pesquisa científica. No âmbito da pesquisa que acabamos de descrever, os textos que escolhemos pertencem, de modo variável, a três patamares. Mesmo que os três se inter-relacionem o tempo todo, poderíamos identificar algumas tendências para cada tipo de discurso. Do lado institucionalizado, a Scientific American Brasil apresenta as teorias ora já avaliadas, ora cujo processo de avaliação está avançado. Os artigos que esta revista de vulgarização apresenta se baseiam na pesquisa especializada, isto é, por exemplo, nos artigos de Astronomy \& Astrophysics, que apresentam resultados com circunscrição menor no campo geral da pesquisa, mas com precisão científica marcante. Os autores tentam dar sentido ao material que coletaram, ou seja, às imagens que percorrem os artigos. Participam da tentativa de interpretação das formas estabilizadas com as implicações indicadas por Dondero. O processo da pesquisa em laboratório funciona segundo outro modelo, porque o caminho da estabilização é muito mais instável.

Veremos, adiante, como os discursos que compõem a pesquisa de laboratório hesitam quanto à identificação dos objetos. Agora que temos esclarecido o contexto no qual nosso trabalho se desenvolve, podemos começar as análises. Seu propósito será explicar e caracterizar o dinamismo dos conteúdos do ponto de vista tensivo, a fim de conseguir uma diferenciação estável dos discursos sobre esta base. Começaremos com os discursos enunciados em laboratórios.

\section{Discurso em laboratório: Center for Astrophysics}

O texto que analisaremos nesta seção vem dos anexos da tese de doutorado em ciências da linguagem e epistemologia das ciências de Catherine Allamel-Raffin (2004, v.2, p. 24-44) ${ }^{6}$. O texto transcrito pela pesquisadora trabalha com a descrição da galáxia 3C129. Por isso, um astrônomo observa vários tipos de imagens realizadas em raio-x e em rádio. Algumas imagens apresentadas foram subtraídas, isto é, os astrônomos retiraram os elementos contidos acima de uma definida intensidade luminosa. Algumas outras resultam de uma sobreposição de uma imagem em raio x subtraída com os contornos de intensidade importados da imagem em rádio. Observaremos então um pensamento que progride graças às imagens. Propomos abordar o texto segundo quatro eixos da descrição tensiva, o modo de presença, a fidúcia, o modo de eficiência e o modo de junção.

\footnotetext{
${ }^{5}$ Para marcar as demais traduções, usaremos o acrônimo T.N.

${ }^{6}$ A tese e os anexos estão disponíveis online no endereço seguinte: http://science-societe.fr/allamel-raffincatherine-\% $2 \%$ AB-la-production-et-les-fonctions-des-images-en-physique-des-materiaux-et-en-astrophysique\%C2\%BB-doctorat-en-epistemologie-et-histoire-des-sciences-et-des-techniques/. As menções "v.1" e "v.2" fazem referência aos volumes da teses. Assim, "v.1" se refere ao primeiro volume dos anexos.
}

Disponível em: http://seer.fclar.unesp.br/casa 


\subsection{Os modos de presença}

Os modos de presença definem, em semiótica tensiva, a modulação da existência de uma unidade que chega ao campo de presença. Trata-se então de uma relação entre um sujeito e um objeto, na qual o objeto é percebido segundo níveis existenciais diferentes. Assim podemos ler em Tensão e significação (FONTANILLE \& ZILBERBERG, 2001), no capítulo dedicado à "presença":

[...] a inanidade (a potencialização) constitui uma perda de densidade existencial, provocada pela anulação do foco, perda que conduz da presença (realizante) à ausência (virtualizante); inversamente, a perda (atualizante) proporciona um ganho de densidade existencial, devido à intensidade do foco, no caminho que leva da ausência à presença. Assim, os dois percursos podem ser representados, respectivamente, como a saída e a entrada por relação ao domínio perceptivo. (FONTANILLE \& ZILBERBERG, 2001, p. 135).

Isso significa que o objeto vai adquirir uma densidade existencial diferente segundo o foco. Essa questão parece pertinente quando se pensa nas imagens astrofísicas. Com efeito, observa-se uma variação forte dos focos e, por conseguinte, das densidades existenciais, na medida em que o discurso se constrói. Esta construção discursiva pertence à tentativa de estabilização das formas, que trabalha com a hipotética elaboração de um objeto científico, como vimos antes. A pesquisa oscila entre os polos de presença, segundo vários percursos, entre realização, potencialização, virtualização e realização. Foi possível observar três tipos de movimento existenciais: da virtualização até a atualização, da potencialização até a virtualização, da potencialização até a atualização.

O primeiro caso, da virtualização que se torna atualização, aparece claramente no trecho seguinte, que comentaremos a seguir:

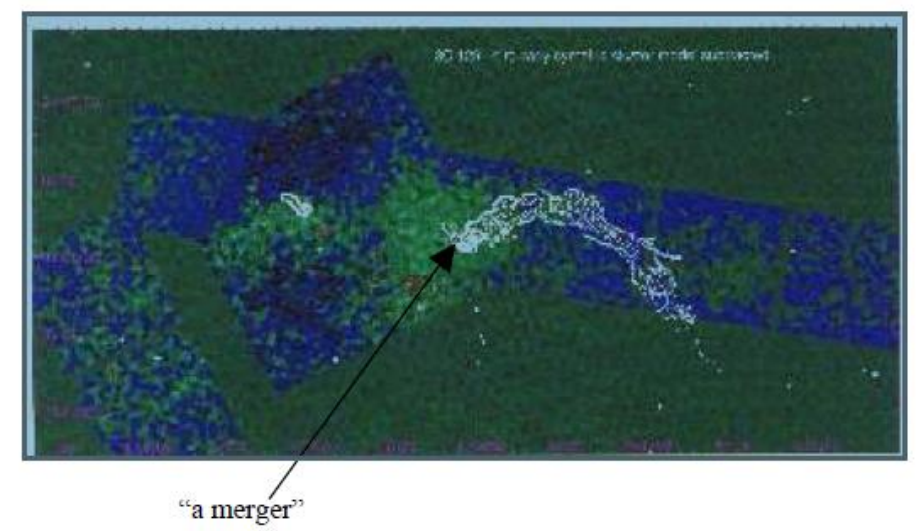

DH: Respect to large positive area around 129. This one is called 3C129.1 and this is 3C129, because when they first made the catalogue, they didn't realize, they were two separate sources. I mean they had poor resolution. Then, later they found there were two sources. So we think there is a merger in this cluster, we thought that a long time ago.

CR: What is a merger? 
DH: When two cluster come together and become gravitationally bound. ${ }^{7}$ (ALLAMEL-RAFFIN, 2004, v.2, p. 30).

A imagem ${ }^{8}$ que está sendo usada é uma sobreposição de uma imagem em raio x subtraída e os contornos de intensidade de uma imagem em comprimento rádio. O exemplo é bastante simples. Na verdade, observa-se a transformação de um objeto virtualizado, ou seja, um objeto de cuja existência não se faz questão, em um objeto atualizado, o merger. Esse tipo de pensamento foi permitido graças às transformações técnicas das visualizações do espaço em imagens mais precisas. Então, é o caminho de uma imagem (ou de algumas imagens) para outras que abriu a possibilidade de constituir um objeto. Um caminho de pensamento diferente poderia ser estudado. Assim, um pouco mais além, no mesmo artigo, encontra-se o trecho seguinte:

DH: Let's turn this into colour. Let's dispose the radio. [...] It may look like the cluster are a lot bigger, but you've got very little area to establish your background, if really it is the cluster, it's going up *this far ${ }^{* 9}$. It would be nice because we have seen a cluster of that far. So, one of the things, you know, we want to know this is: is the intensity here lower then here and here? $?^{10}$

$[\ldots]$

DH: I can't convince myself. It could be a tiny peak. It's not good enough to tell you know. I can't see no difference here. ${ }^{I I}$

(ALLAMEL-RAFFIN, 2004 v.2, p. 31-32).

Pode-se ver o que aconteceu com o grau de presença do objeto. Começando a observação, a modificação da imagem faz aparecer um alongamento potencial do objeto, que apresenta uma presença potencializante tônica, prestes a ocorrer: "if really it is the cluster" e "is the intensity here lower than here and here?". Continuando a análise, o astrônomo percebe que as diferenças de intensidades não permitem afirmar um objeto com densidade existencial. Isso desemboca em uma virtualização do objeto ("I can’t see no difference

\footnotetext{
${ }^{7}$ DH: Em respeito à grande área positiva em torno de 129. Esta é chamada 3C129.1 e esta é 3 C129 porque quando fizeram o primeiro catálogo não perceberam que eram duas fontes diferentes. Quero dizer, eles tinham uma resolução muito fraca. Mais para frente eles descobriram que havia duas fontes. Então nós achamos que existe um merger nesse cluster, nós pensamos nisso já faz bastante tempo.

CR: O que é um merger?

DH: quando dois clusters se juntam e se tornam gravitacionalmente encadeados. (ALLAMEL-RAFFIN, 2004, v.2, p. 30 , T.N.)

${ }^{8}$ Não colocaremos nenhuma legenda além das ofertadas pelos astrônomos nas fontes respectivas. A razão dessa ausência é que seria inútil tentar legendar imagens que já estão sendo legendadas. Por isso, bastaram os comentários dos pesquisadores ou as legendas colocadas pelos artigos. Quanto às tabelas próprias ao nosso artigo, estas serão devidamente referenciadas.

${ }^{9}$ As estrelas correspondem às passagens transcritas em vermelho por Allamel-Raffin, quando não está certa da palavra ou do trecho. Ela explicou essas indecisões devido à qualidade da gravação.

${ }^{10}$ Vamos colocar isso em cores. Vamos colocar o rádio. [...] pode parecer que o cluster é muito maior, mas você considerou uma área muito pequena para estabelecer seu background, se isso é realmente o cluster, ele está subindo *até aqui*. Seria legal porque nós já vimos um cluster até ali. Então, sabe, uma das coisas que a gente quer saber é: a intensidade aqui é menor que aqui e aqui? (ALLAMEL-RAFFIN, 2004, v.2, p. 31-32, T.N.).

${ }^{11} \mathrm{DH}$ : Não consigo me convencer. Poderia ser um minúsculo pico. Não é bom o suficiente para dizer é isso. Não consigo ver nenhuma diferença aqui. (ALLAMEL-RAFFIN, 2004, v.2, p. 31-32, T.N.).
}

Disponível em: http://seer.fclar.unesp.br/casa 
here”). Finalmente, poderíamos ver um processo inverso duas páginas mais além, quando o pesquisador está observando o centro do cluster:
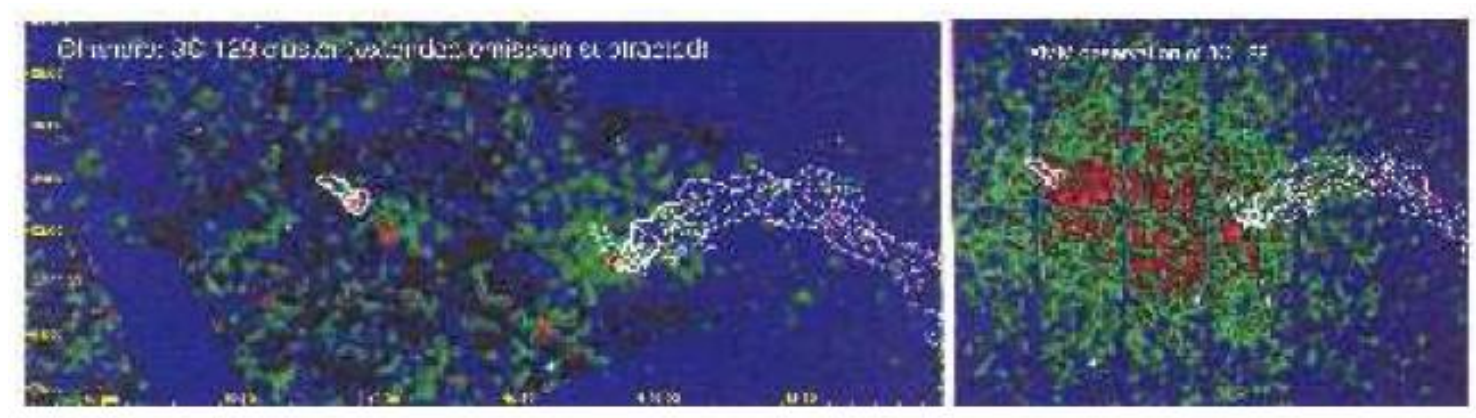

[...] So my statement about the cluster center, I think still [inaudible] in the sense that, there is a slight enhancement of brightness here. So it's obviously $a * X$-shape* cluster. You can't trust this area because you're getting at the edge of the detector, so you don't know what's going on here. But, in this direction here, we got a pretty good shape.

$[\ldots]$

(passa de Chandra até XMM)

DH: [...] it seems it would be a significant difference: these numbers are all around in the 40, you only get into 30 when you're going to this, around the radio source. So that's nice. So, that's we were looking for it, originally. We never could see it in this particular source. 12

(ALLAMEL-RAFFIN, 2004, v.2, p. 36-37).

Nessa parte, o astrônomo descreve o centro hipotético do cluster. Na verdade, os cientistas que trabalham nesse artigo pensam que o centro do cluster não se situa no lugar em que se costuma representá-lo. A descrição anterior é feita como objetivo de garantir esse ponto de vista. Nesse momento da análise, DH está usando as duas imagens de Chandra e de XMM, uma delas sendo subtraída, e a outra não, ambas apresentando a adição dos contornos rádio. No começo, ele observa, na imagem de Chandra, um elemento que o leva a considerar um objeto potencial: a luminosidade que sobressai ("there is a slight enhancement of brightness"). Essa fica potencializada por causa de uma dúvida técnica (edge of the sensor). Continuando a pesquisa, o astrônomo compara as imagens e pode concluir a atualização do objeto graças à outra ${ }^{13}$ do XMM que confirma a presença do objeto potencializado na primeira: "that's we were looking for". Há então uma passagem do potencial ao atual.

\footnotetext{
${ }^{12}$ [...] Então minha afirmação sobre o centro do cluster, eu ainda acho [inaudível] no sentido de que há uma leve acentuação de luminosidade aqui. Então é óbviamente um $X$-shape cluster. Você não pode confiar nesta área porque está considerando a borda do detector, então você não sabe o que está ocorrendo aqui. Mas, nesta direção, nós temos uma forma muito boa.

$[\ldots]$

(Passa de Chandra até XMM)

DH: [...] parece que seria uma diferença significante: esses números são todos próximos a 40, você só chega em 30 quando você vem para esse, em torno da fonte rádio. Então é legal. Então é isso o que estávamos procurando originalmente. Nunca tínhamos conseguido ver isso nessa fonte particular. (ALLAMEL-RAFFIN, 2004, v.2, p. 36-37, T.N.).

${ }^{13}$ Trata-se de uma prática padrão nas pesquisas astronômicas que se chama Interinstrumentalidade. Os cientistas podem chegar a um grau maior de certeza graças à colaboração de várias representações visuais, desviando assim dos erros devidos aos artefatos do material ou das condições meteorológicas. Para ler o conceito colocado no contexto da pesquisa, ver: Raffin, 2004, v.1, p. 309-329.
}

Disponível em: http://seer.fclar.unesp.br/casa 
Os três tipos de movimento ao redor das modalidades de presença mostram que a progressão do sentido da imagem não é definitiva e permanece em busca de estabilização, ou seja, de iconização no sentido de Bordron. É preciso fazer duas notas a respeito dessa observação. A primeira corresponde a levar em conta o fato de que o grau de presença nunca atinge a realização. $\mathrm{Na}$ realidade, são poucos os discursos que apresentam uma realização certa do objeto, sobretudo nos casos estudados nos quais se trata de objetos não diretamente visíveis e cujo comportamento permanece apenas parcialmente conhecido. Sem atingir a realização, o grau maior de atualização (o mais próximo da realização, então) que poderíamos encontrar aparece nos casos da ciência institucionalizada. O tipo exemplar situa-se nas revistas de vulgarização, como veremos. A segunda nota é que o reconhecimento dos objetos e das suas modalidades de presença depende fortemente do modo de compor o valor desses objetos. Dessa maneira, reconhecer um objeto astrofísico corresponde a efetuar uma correlação entre dois eixos, a posição e a intensidade, o que nos leva ao estudo da composição tensiva do valor.

\subsection{Valor, junção e eficiência ${ }^{14}$}

A semiótica tensiva reconhece o valor como outro polo da definição do sentido, além da modalidade existencial. Ela explica o valor como intersecção entre duas valências situadas nos eixos da extensidade e da intensidade. A extensidade dá conta da "quantidade, [d]a variedade e [d]a extensão espacial ou temporal de uma unidade" (HÉBERT, 2009, p. 64, T.N.). A intensidade atua como eixo que governa a extensidade. Para defini-la, reconhece-se o andamento e a tonicidade. $\mathrm{O}$ andamento oscila entre o rápido e o lento, enquanto a tonicidade oscila entre o tônico e o átono. A projeção dos dois eixos define um estilo tensivo, ou seja, o tipo de dinamismo das unidades logo que estão ligadas, o que se pode caracterizar graças aos modos de eficiência, de existência ${ }^{15}$ e de junção. O modo de eficiência caracteriza o modo de chegada de uma unidade no campo de presença. A definição deste modo é governada pela descrição do valor, de tal modo que um comportamento rápido (andamento) e tônico (tonicidade) explica o sobrevir, que atua de repente. Ao contrário, uma unidade que seria atualizada como lenta e átona participaria do pervir, que consegue pouco a pouco. O modo de existência corresponde "às consequências subjetais da autoridade do modo de eficiência" (ZILBERBERG, 2011, p. 14, T.N.), isto é, que dá conta do tipo de tratamento que recebe o sujeito cognitivo. Ora ele é "apreendido", o que significa que o sujeito é depreendido da intencionalidade fenomenológica (2011, p. 14, T.N.) e que é um sujeito que sofre, ora ele foca, quer dizer que há uma intencionalidade que se exerce. Finalmente, o modo de junção formula "as consequências objetais da autoridade do modo de existência" (2011, p. 15) e diz respeito às relações entre as unidades no campo de presença, para saber se entre elas existe uma relação de implicação (do tipo "se a, então b") ou de concessão (do tipo "embora a, entretanto b").

Como as oposições da semiótica tensiva são geralmente binárias, poderíamos dizer, seguindo Zilberberg, que ao sobrevir corresponde a apreensão, uma extensidade restrita, uma junção concessiva e, por conseguinte, um andamento rápido e uma tonicidade tônica, enquanto ao pervir corresponde o foco, uma junção implicativa, a extensidade máxima, um

\footnotetext{
${ }^{14}$ A apresentação dos conceitos é uma retomada da descrição efetuada por Zilberberg em Des formes de vie aux valeurs (ZILBERBERG, 2011).

${ }^{15}$ Segundo os casos, a modalidade existencial caracteriza tanto a modalização do campo de presença (o que vimos na seção anterior com Tensão e significação) quanto às consequências subjetais do sobrevir e do pervir que explicaremos nesta seção com Des Formes de vie aux valeurs.
}

Disponível em: http://seer.fclar.unesp.br/casa 
andamento lento e uma tonicidade átona. A tabela 1 retoma a caracterização dos modos e a composição do valor. Não existe entre as células uma relação de reciprocidade direta, quer dizer, a intensidade não corresponde ao modo de eficiência. Os elementos estão na mesma tabela para facilitar a síntese. No entanto, com certeza, há uma relação necessária entre as partes, de tal modo que o tipo de composição do valor define uma eficiência particular, que implica um tipo de existência e, consequentemente, uma determinada junção.

\begin{tabular}{|c|c|}
\hline \multicolumn{2}{|c|}{ SENTIDO } \\
\hline MODOS & VALOR \\
\hline $\begin{array}{l}\text { Modo de eficiência (como a unidade chega no } \\
\text { campo de presença). } \\
\text { Sobrevir vs. Pervir }\end{array}$ & $\begin{array}{l}\text { Intensidade } \\
\text { Tonicidade: tônico } v s \text {. átono } \\
\text { Andamento: rápido } v s \text {. lento }\end{array}$ \\
\hline $\begin{array}{l}\text { Modo de existência ("as consequências subjetais } \\
\text { da autoridade do modo de eficiência") } \\
\text { Apreensão vs. Foco }\end{array}$ & $\begin{array}{l}\text { Extensidade } \\
\text { Espacialidade: concentrado } v s \text {. difuso } \\
\text { Temporalidade: breve } v s \text {. longo }\end{array}$ \\
\hline $\begin{array}{l}\text { Modo de junção ("as consequências objetais da } \\
\text { autoridade do modo de existência") } \\
\text { Concessão vs. Implicação }\end{array}$ & \\
\hline
\end{tabular}

Podemos agora retomar o nosso texto transcrito a fim de entender que tipo de unidade ele apresenta e segundo quais modos. Dissemos antes que é preciso descrever como se compõe o valor do objeto astrofísico com o intuito de chegar à compreensão fina do processo de aquisição de um determinado sentido para uma imagem. Seguindo a ordem proposta pela semiótica tensiva, podemos começar com a exposição da composição do valor como projeção da intensidade sobre a extensidade. Se retomarmos o segundo exemplo usado na exposição dos modos de presença, entenderíamos como se articulam os elementos pertinentes:

DH: [...] It may look like the cluster are a lot bigger, but you've got very little area to establish your background, if really it is the cluster, it's going up *this far*. It would be nice because we have seen a cluster of that far. So, one of the things, you know, we want to know this is: is the intensity her lower then here and here? (grifo nosso)

$[\ldots]$

DH: I can't convince myself. It could be a tiny peak. It's not good enough to tell you know. I can't see no difference here.

(ALLAMEL-RAFFIN, 2004, v.2, p. 31-32).

Durante todo o tempo de pesquisa, o astrônomo tenta definir a existência dos objetos e caracterizá-los. O processo inteiro está baseado em uma correlação entre a posição de um ponto e a sua intensidade de rádio, $x$, fotônica, etc. Esse movimento, no trabalho, permitiu também efetuar os contornos de rádio que foram importados para a imagem em raio x subtraída. Esses contornos apresentam a variação de uma intensidade segundo uma posição. Além disso, a constituição dos objetos funciona no reconhecimento das diferenças de intensidade entre essas posições, ou seja, ao reconhecer a tendência da quantificação intensiva

\footnotetext{
${ }^{16}$ Extraímos todas as citações desta tabela do primeiro capítulo de Des formes de vie aux valeurs, nas primeiras linhas das subseções adequadas. (ZILBERBERG, 2011, p. 7-23).
} 
até o mais ou até o menos ("is the intensity here lower then here and here?"). Geralmente, no processo, o modo de eficiência da unidade assim definida corresponde ao pervir, o que pressupõe foco e implicação. Com efeito, as correlações podem ser observadas graças aos tipos de manipulação efetuados anteriormente.

Assim, se o astrônomo opera uma redução geral das intensidades, como no caso das imagens subtraídas, ele não pode esperar ter grandes diferenças de valores. Em outros casos, quando ele opera uma sobreposição de imagens, ele espera ter uma coordenação sem erros destas, de modo que seja possível efetuar análises posteriores, como no caso da observação de correlação de densidade entre as emissões rádio e em raio x. No entanto, acontece às vezes que o modo de junção mude e se torne concessivo, enquanto a eficiência se torna sobrevir, e a existência, apreensão. Podemos observar este caso nos trechos seguintes, nos quais DH está surpreendido com os objetos que aparecem nas imagens:

DH: [...] It's funny. I mean if you were presented with these data, you would think that the center of the cluster is about here. So where is the brightest point in the cluster? ${ }^{17}$

(ALLAMEL-RAFFIN, 2004, v.2, p. 33)

DH: [...] See what... This kind of behavior, it doesn't make much sense to me... This is fairly significant, I mean that's 16 and over it 5. It's fairly a big change, we're not just seeing just a slight noise fluctuation, it seems to me.

[...]. With Chandra we saw a fairly obvious source associated with this.

$[\ldots]$

DH: [...] What's about it? You see there is something in here because there is no source there ! ${ }^{18}$

(ALLAMEL-RAFFIN, 2004, v.2, p. 35)

Com esses exemplos, temos dois tipos de concessões diferentes que se opõem sobre uma base fiduciária. Na semiótica tensiva, a fidúcia caracteriza a questão da crença e da confiança. Os dois termos se distinguem segundo o tipo de relação que os fundamentam. Assim, nas linhas de Tensão e significação, podemos ler que a crença está baseada em uma relação sujeito-objeto, enquanto a confiança está baseada na relação sujeito-sujeito (FONTANILLE \& ZILBERBERG, 2001, p. 264-265). Essa partição implica dois tipos sintagmáticos de organização dos campos da crença e da confiança, articulados, respectivamente, segundo um fazer crer por um lado e pelo embate entre dois querer parecer por outro lado (FONTANILLE \& ZILBERBERG, 2001, p. 268-269), dos quais resultam os dois esquemas sintagmáticos seguintes:

\footnotetext{
${ }^{17}$ DH: É curioso. Quero dizer, se você fosse apresentado com esses dados, você pensaria que o centro do cluster é mais ou menos aqui. Então onde está o ponto mais luminoso no cluster? (ALLAMEL-RAFFIN, 2004, v.2, p. 33, T.N.).

${ }^{18}$ DH: [...] Quer saber... esse tipo de comportamento não faz muito sentido para mim... Isso é bastante significante, quero dizer, aqui é 16 e acima 5. É consideravelmente uma grande mudança, não estamos vendo apenas uma pequena variação de ruído, me parece. [...] Com Chandra nós vimos uma fonte bastante óbvia associada a isso.

[...]

DH: [...] Como assim? Você vê que tem algo aqui porque não há nenhuma fonte lá! (ALLAMEL-RAFFIN, 2004, v.2, p. 35).
} 


\section{CONFIANÇA}

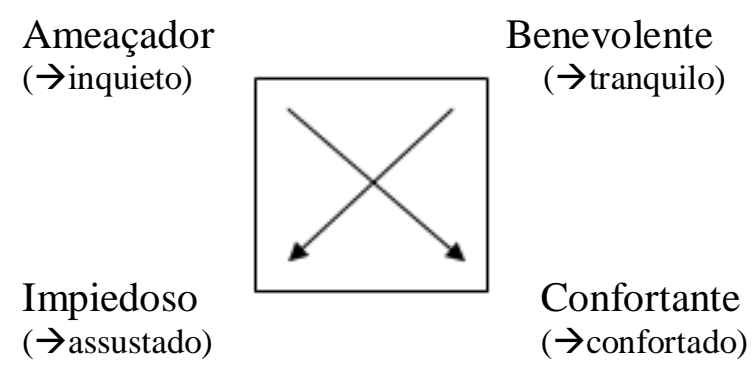

\section{CRENÇA}

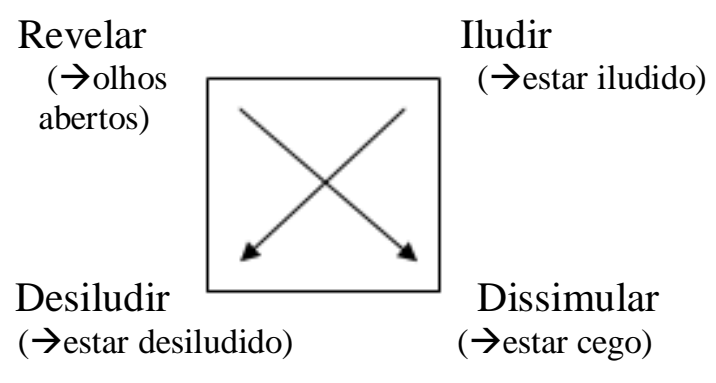

Nessa perspectiva, o primeiro caso apresenta uma relação assimétrica entre o fazer crer da imagem e a resposta do pesquisador. Embora a imagem esteja iludindo o astrônomo com "these datas", ele fica de "olhos abertos" de modo implícito, dizendo que "you would think", ou seja, recorrendo a uma condicional cujo efeito é recusar uma tal afirmação de crença falsa. Então, nesse primeiro caso, a concessão funciona do modo seguinte: "embora a imagem pareça a, entretanto é não a". No segundo caso, parece que estamos também numa relação entre imagem e pesquisador, o que indicaria uma relação sujeito-objeto, implicando a crença como último recurso. No entanto há duas diferenças. Em primeiro lugar, a imagem é percebida como tendo uma "força ilocutória" (segundo as próprias palavras do Zilberberg) dada pelo fato de que seja um simulacro, um parecer: "You see there is something here". Em segundo lugar, embora o resultado seja um crer, o embate entre as duas imagens pressupõe dois querer parecer "confortantes".

Da mesma maneira que no primeiro exemplo, a resposta do pesquisador é assimétrica, já que oferece um parecer "inquieto": "What's about it? You see there is something in here because there is no source there!". A concessão funciona então segundo um modelo diferente, que seria: "embora a e não $a$, entretanto não a". Para voltar brevemente aos modos de existência (no sentido da modalização do objeto), poderíamos formular uma conclusão intermediária a respeito desta seção sob a forma de uma concessão. Assim, embora pudéssemos pensar, com o exemplo da segunda concessão, que a pesquisa científica virtualiza necessariamente as potencializações não atualizadas ("no source there" implica uma ausência de objeto), entretanto temos que reconhecer, como se dá no primeiro exemplo, que a ciência atualiza (e quase realiza) algumas realidades potenciais que vários exemplos virtualizam (a ausência de centro no cluster não impede de pensar que ele está lá).

\section{Discursos de revista especializada e de vulgarização: Astronomy \& Astrophysics e Scientific American Brasil}

A passagem dos discursos em laboratórios aos de revistas especializadas ou de vulgarização corresponde à passagem da tentativa de estabilização das formas ao reconhecimento de que as formas já estão estabilizadas, pelo menos provisoriamente. Por isso, os modos de descrição das imagens também mudam, de tal modo que não poderíamos apresentar o mesmo tipo de explicação, especialmente quanto à definição das unidades. Enquanto, no laboratório, o objeto se caracteriza graças à correlação entre determinadas posições e intensidades, nos artigos, os elementos são descritos como determinados pela posição e nome, já que são estabilizados como objetos reconhecíveis. Nessa perspectiva, podemos considerar que o eixo da extensidade não muda muito. Ele ainda assume a função de 
delinear uma porção espacial do objeto, ou um tipo de abertura, de concentração, de temporalidade. A qualificação e a quantificação intensas, porém, mudaram da mera luminosidade do comprimento de onda para uma quantificação da intensidade de outro objeto. Este outro objeto, que descreveremos um pouco mais adiante, dá conta do fato de que não se pode tratar da mesma intensidade, já que o texto de legenda constituído não participa do mesmo propósito que o texto de descrição em laboratório. Enquanto este último trabalha a estabilização icônica, a legenda do artigo especializado afirma ou pressupõe a estabilização, propondo a imagem à comunidade científica, ou usando-a como imagem já padronizada, segundo o grau de novidade do objeto. Precisaremos da paciência do leitor para os próximos desenvolvimentos - longos, mas necessários - para explicar como se estruturam os discursos deste segundo gênero aos olhos da perspectiva tensiva.

Não podemos propor uma análise tensiva que seja inteiramente simétrica, no sentido da correlação posição-luz. O que há, então, além de tal qualificação do objeto enquanto posição e luz? O exemplo ${ }^{19}$ seguinte poderá esclarecer o nosso ponto de vista:
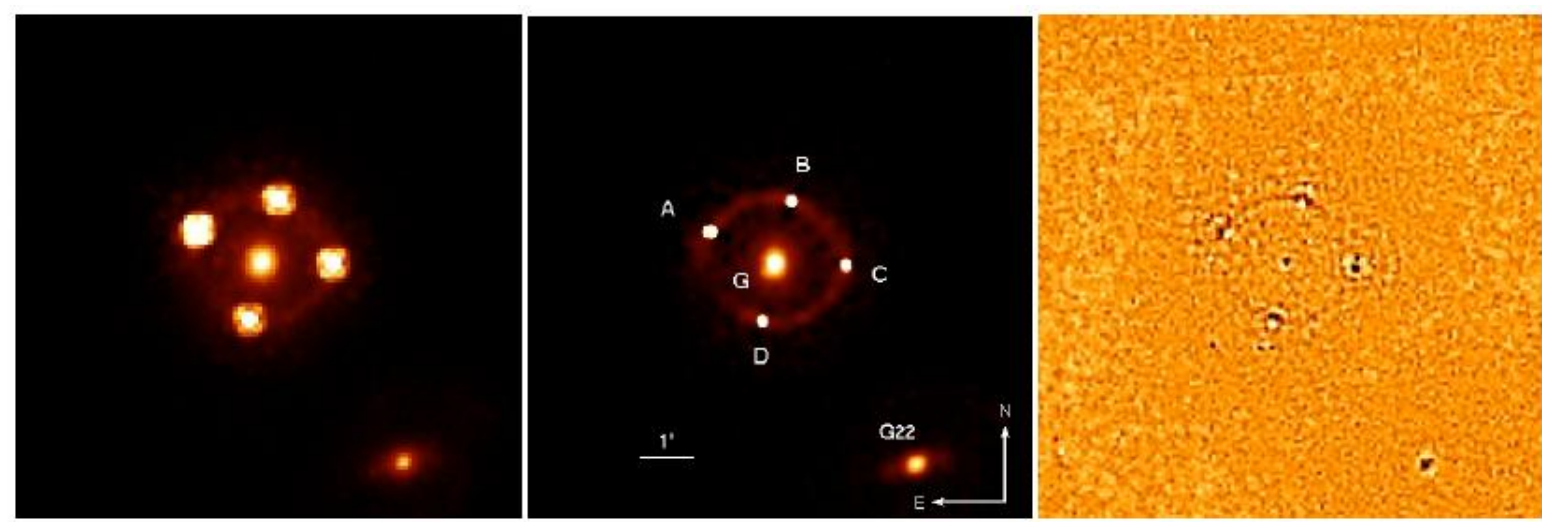

Fig. 4. Left: Combination of the four original HST/NIC2 F160W frames of HE 0435-1223. The field of view is $9 \times 9$ arcsec. Middle: Deconvolved image, where the lensing galaxy is modeled as a de Vaucouleurs profile (see text). The nearest galaxy on the plane of the sky, G22 (Morgan et al. 2005 ), is also indicated. Right: Residual map in units of the noise. The colour scale ranges from $-4 \sigma$ (white) to $+4 \sigma$ (black).

Essa imagem vem de um artigo apresentado por dez astrônomos de várias instituições, que trata de um modelo particular de observação usando funções matemáticas que permitem melhorar as imagens. ${ }^{20}$ Há dois pontos interessantes em relação ao nosso propósito. Por um lado, observa-se que a correlação simétrica de descrição tensiva permanece com a última frase: "The colour scale ranges from $-4 \sigma$ (white) to $+4 \sigma$ (black)". Ela estabelece uma vinculação entre escala de cor e intensidade, ou seja, correspondência entre posição e luz. Isso funciona da mesma maneira que observamos no discurso de laboratório. Por outro lado, já que se situa em um grau além da mera descrição iconizante, o texto opera uma explicação das operações que foram feitas com as imagens. Há também uma nota, breve e importante, que convida o leitor a voltar ao texto - "(see text)" -, a qual é capital na situação tensiva da legenda. Com efeito, ela abre a porta para considerações a respeito da descrição tensiva assimétrica entre os eixos da intensidade e da extensidade. Para explicar tal estado, faremos um desvio por um texto de Louis Hébert (2009). Na verdade, trata-se de uma nota de rodapé

\footnotetext{
19 À esquerda: combinação dos quatro HST/NIC2 F160W quadros originais de HE 0435-1223. O campo de visão é 9x9 arcsec. Ao centro: Imagem de deconvolução em que a lensing galaxy é modulada de acordo com o perfil de Vaucouleurs (ver texto). A galáxia mais próxima do plano do céu, G22 (MORGAN et al. 2005), está também indicada. À direita: mapa residual em unidades de ruído. A escala de cores varia de $-4 \sigma$ (branco) a $+4 \sigma$ (preto). (COURBIN et al., 2010, T.N.).

${ }^{20}$ COURBIN et al., 2010.
} 
que o autor escreve num capítulo a respeito da análise tensiva (2009, p. 63-85). Ele faz a seguinte pergunta:

Pode-se colocar uma valência composta num eixo? Se a resposta for sim, poderíamos então distinguir entre uma utilização analítica do esquema tensivo e uma utilização sintética. A utilização sintética se autoriza a situar em um dos eixos uma valência composta: assim, colocaremos no eixo das intensidades a intensidade de um elemento outro que o que se situa no eixo da extensidade; por exemplo, a intensidade da avaliação positiva atribuída ao conhecimento (valência composta, enquanto a intensidade atribuída ao conhecimento seria uma valência simples) poderia aumentar em função da extensão do conhecimento (valência simples). (HÉBERT, 2009, p. 64, T.N.).

Para nosso desenvolvimento, tal nota explicaria como poderíamos distinguir as qualificações tensivas atribuídas à variedade de discursos. Por um lado, com o discurso em laboratório, fizemos um uso analítico do esquema tensivo, reconhecendo uma correlação simétrica entre posição dos pontos e intensidade da luz. Por outro lado, poderíamos identificar um uso que seria sintético nos demais discursos, isso é, nos textos de artigos especializados e de vulgarização. A questão que é preciso levantar agora é: o que há no eixo da intensidade senão a intensidade do ponto? Ao examinar as legendas que tomamos das revistas de vulgarização, achamos que a resposta não fica muito longe da fidúcia, como foi o caso na seção anterior. O exemplo seguinte, tirado da Scientific American Brasil, ${ }^{21}$ ajudará a nossa compreensão:

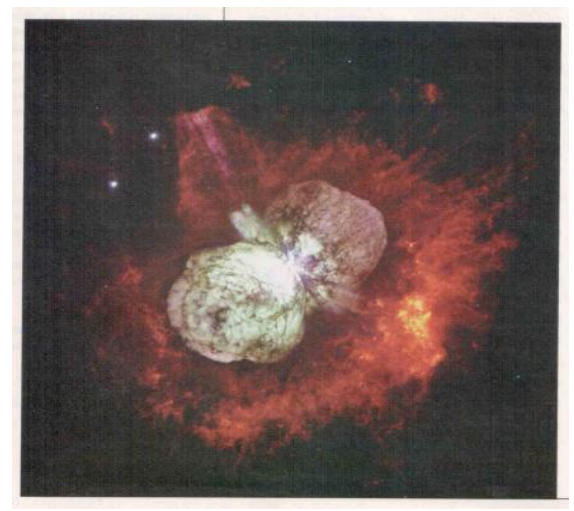

Em relação à legenda anterior, além da desaparição da descrição tensiva analítica e dos modos de enunciação da imagem, podemos observar que o texto opera duas modificações importantes. A primeira é que não faz nenhuma referência ao texto do corpo do artigo. A segunda, que é o correlato da primeira, é que a legenda aparece como autossuficiente quanto a qualificar os seus componentes e o seu propósito. Assim, segue tratando de um objeto que podemos definir, de modo extenso, como posição no espaço. Mas, no nível intenso, o que distingue "see text" e "com os dados do Fuse foi possível identificar os sinais espectrais de duas estrelas separadas.”? E, no mesmo nível, o que distingue ambas formulações com a mera projeção posição-intensidade luminosa? Achamos que se trata do "saber", entendido como acessibilidade ao conhecimento (FONTANILLE \& ZILBERBERG, 2001, p. 266), ou seja, ao objeto.

\footnotetext{
${ }^{21}$ ARTERO, 2005.
} 
No capítulo dedicado a "fidúcia" de Tensão e significação, Fontanille \& Zilberberg situam o saber em relação ao conhecer e o crer. Na realidade, é o crer que está sendo definido como "consequência de um complexo discursivo [...] conhecer+saber+crer" (FONTANILLE \& ZILBERBERG, 2001, p. 265). Nessa perspectiva, o conhecer caracteriza um sujeito que tenta "penetrar" um objeto, quando o saber depende da "acessibilidade desse conhecimento" (2001, p. 266). Por fim, o crer, como vimos, "acrescenta ou não um valor de verdade" (2001, p. 266). O saber, então, pode ser definido como maior ou menor dificuldade - ou facilidade - de acesso ao conhecimento, como também, como tonicidade e andamento. $\mathrm{O}$ saber varia então na medida em que o conhecimento seja o resultado de um processo lento ou rápido de aproximação (andamento) e na medida em que este mesmo conhecimento tiver ou não importância a respeito da pesquisa (tonicidade).

Colocado no eixo da intensidade, o saber permitiria distinguir os dois tipos de discursos segundo a perspectiva tensiva. Do lado dos discursos de especialização nas revistas, trata-se de objetos pouco extensos, os autores cuidam de uma pequena porção de interesse no objeto: medida astrométrica, modos de deconvolução, etc. Por isso o objeto do artigo de especialização se caracteriza por sua concentração. Do lado da vulgarização, trata-se de objetos extensos, que possuem um grau maior de extensidade graças ao fato de que são objetos gerais, difusos quanto à precisão da análise que lhes devotam os autores; estão em um ponto de convergência de várias análises especializadas, perdendo, por isso, a sua concentração. Quanto à intensidade dos dois tipos de discursos, se a articularmos ao redor do saber, eles se diferenciarão do seguinte modo: a especialização anda, passo a passo, apresentando imagens com legendas que são pontos ínfimos mesmo que importantes no processo da pesquisa. Por isso, quanto a definir o andamento e a tonicidade, ambos estão no "menos". Ou seja, o andamento é lento, a progressão até a novidade científica se efetua passo a passo, ${ }^{22}$ e a tonicidade é átona, pelo menos em relação à tonicidade da vulgarização. Essa última apresenta uma parte dos resultados estabilizados das pesquisas científicas especializadas. Podemos qualificá-la com um andamento rápido, já que ela oferece atalhos cognitivos. Por exemplo, quando a legenda disse que "a nuvem de gás e poeira [...] dificulta o trabalho dos astrônomos, mas [que] foi possível identificar os sinais espectrais de duas estrelas separadas", ela dá uma informação que careceu de muitas pesquisas especializadas.

Quanto à tonicidade, dissemos antes que fica forte em relação à tonicidade dos artigos de especialização. Isso pode ser entendido com o modo concessivo de apresentar os resultados. Se é possível dizer, de acordo com Zilberberg, que a concessão "está no princípio do acontecimento, este não-sei-quê que faz com que a apreensão se distinga do foco e projete uma profundidade inédita" (ZILBERBERG, 2010, p. 325, T.N.) com uma saturação das valências intensivas, então a legenda vulgar funciona como acontecimento tônico, segundo o modelo "embora a nuvem de gás e poeira [...] dificulte o trabalho, entretanto foi possível identificar uma estrela dupla" (enfatizamos).

Colocado no eixo da intensidade, o saber permitiria também reforçar a distinção entre o uso analítico do esquema tensivo aplicado aos objetos astrofísicos, no qual o crer organiza intensivamente a relação sujeito-objeto, e seu uso sintético, no qual o saber atuaria o papel intensivo. Aplicada ao entendimento do valor da unidades em astrofísica, a distinção saber-crer é elegante por sua simplicidade e possui um alto grau de discriminação e de organização dos discursos observados.

\footnotetext{
${ }^{22}$ A lentidão da progressão assinala-se com a correferência entre as imagens e o texto do corpo do artigo (see text), mas também com notas que se referem a pesquisas anteriores. Cf. Morgan et al. ou de Vaucouleurs profile no nosso exemplo.
}

Disponível em: http://seer.fclar.unesp.br/casa 
Os esquemas apresentados abaixo sintetizam os desenvolvimentos iniciados na segunda seção com os discursos de laboratório e prosseguidos com os discursos de revistas de vulgarização e de revistas especializadas. Cada curva apresenta uma tensão entre duas unidades do nosso corpus, tensão que se constrói ora dentro de uma projeção analítica (à direita), ora dentro de uma projeção sintética (esquerda), segundo o tipo de composição do valor, ou seja, segundo esteja o crer ou o saber sobre o eixo da intensidade.
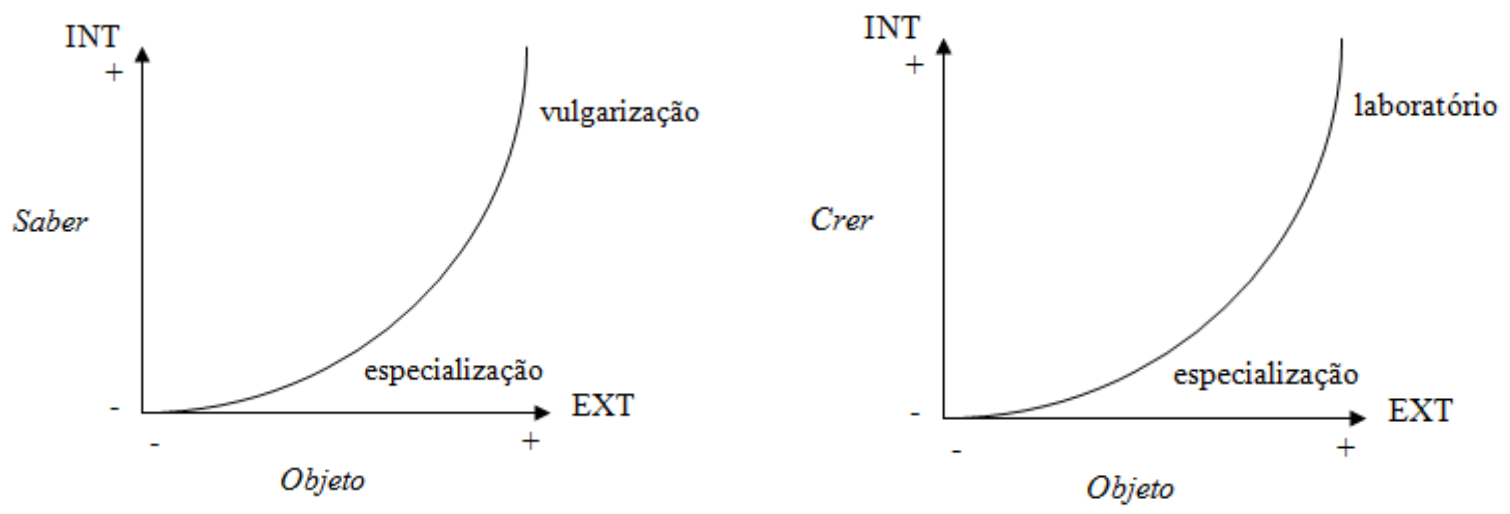

Finalmente, para definir os modos de eficiência e de existência decorrentes dos esquemas, só é preciso utilizar uma implicação teórica. Assim, se a cada modo de junção corresponde um tipo de valor dado pela projeção das valências, a cada um deles correspondem também uma eficiência e uma existência definidas. A primeira seria orientada segundo o pervir logo que o discurso se caracteriza pela atonia e a lentidão da implicação e de acordo com o sobrevir, quando aparece a saturação intensiva da concessão. Quanto às consequências subjetais, elas são governadas pela apreensão no sobrevir e pelo foco no pervir.

Aproximamo-nos do fim do nosso percurso de descrição tensiva das relações entre as imagens e as legendas. Resta-nos, antes de relacionar as análises, caracterizar os aspetos dos modos de presença para os dois últimos discursos de revista. Já fizemos algumas considerações a respeito na primeira seção e, em realidade, os modos de presença não constituem um ponto de interesse forte neste caso. Com efeito, observamos, sem surpresa, que a vulgarização apresenta o grau maior de atualização, que se aproxima, ao máximo, da realização dos objetos. Não há espaço para dúvidas nesses discursos ou, ao menos, pouco espaço, já que dão conta de um universo de formas estabilizadas e aceitas pela comunidade científica. Estamos, então, do lado da institucionalização apontada por Dondero. Ao contrário, podemos ver que os artigos especializados oscilam entre duas tendências, isto é, entre afirmação do objeto e dúvida a respeito dele. A pesquisa escrita se situa, então, entre o potencial e o atual. Algumas das operações matemáticas apresentadas nas legendas mudam o estatuto da imagem até a potencialização por causa de uma falta de certeza. Por outro lado, logo que os modelos foram aceitos, o estatuto da presença muda para a atualização.

\section{Para concluir}

A reflexão a respeito da organização dos discursos na astrofísica que propomos neste trabalho nos levou a analisar as estruturas tensivas de uma parte da variedade discursiva do domínio. Por isso, pegamos três fontes: a primeira foi a transcrição de uma pesquisa em laboratório, a segunda e a terceira - analisadas juntamente por razões metodológicas - foram artigos de especialização e de vulgarização. Permitiram diversas demonstrações: em primeiro 
lugar, uma análise articulada ao redor dos modos de presença corrobora as perspectivas de Dondero a respeito da organização do fluxo da pesquisa. Assim, no nível macroscópico, podese identificar tendências 1. necessariamente atualizantes do lado das formas institucionalizadas (Scientific Amercian Brasil), 2. tendências tanto atualizantes quanto potencializantes do lado das formas bastante estabilizadas (Astronomy\&Astrophysics) e 3 . tendências atualizantes, potencializantes e virtualizantes do lado das formas sendo estabilizadas $(C f A)$. A mesma análise dos modos de presença apresentou algumas orientações particulares deste fluxo do ponto de vista microscópico, na consideração de conteúdos específicos. Foi este o caso principalmente do discurso em laboratório com o foco nas operações de modalização. $O$ correlato desta passagem da pesquisa de estabilização à estabilização aceita levou em consideração uma organização diferenciada da dinâmica dos conteúdos, articulada, em primeira instância, pelo grau de composição dos funtivos que compõem o valor das unidades, ou seja, em função de que a medida colocada no eixo da intensidade seja composta ou não. Isso definiu dois usos do esquema tensivo, seguindo Louis Hébert (2009, p. 64), um uso analítico, que reconhece uma projeção simétrica entre os eixos, e um uso sintético, que dá conta de uma projeção assimétrica dos eixos. Uma tal articulação corresponde à distinção entre formas sendo estabilizadas até o iconismo - no sentido de Dondero - e já estabilizadas, ou seja, à diferenciação entre, por um lado, os discursos de laboratório e, por outro lado, os discursos de revistas de vulgarização e especializadas.

Foi então possível reconhecer duas áreas nas quais atuam as operações que governam a dinâmica dos conteúdos, a implicação e a concessão. Essas áreas estão coordenadas segundo os campos do crer e do saber, ligados às definições tensivas dos objetos (analítica ou sintética). As duas áreas permitiram apontar as diferenças 1. entre discursos de laboratório e discursos de revistas especializadas dentro da projeção simétrica (crer) e 2. entre os discursos de revista especializada e de revista de vulgarização dentro de um esquema com intensidade sintética (saber). Assim, na tabela seguinte :

\begin{tabular}{l|c|c|c|} 
Tipo de esquema tensivo & \multicolumn{2}{|c|}{ Snalítico } & Saber \\
\hline Campo das operações lógicas & \multicolumn{2}{|c|}{ Crer } \\
\hline Tipos de discurso envolvidos & $\begin{array}{c}\text { Caboratório } \\
\text { Especialização }\end{array}$ & laboratório & $\begin{array}{c}\text { Especialização } \\
\text { Vulgarização }\end{array}$ \\
\hline
\end{tabular}

A tabela 2 retoma o modo de organização tensivo do corpus. O discurso de laboratório pertence quase totalmente a uma descrição analítica das unidades e se articula ao redor do crer, dividido em crença e confiança. No caso da confiança, trata-se de um embate de pontos de vista sobre um objeto potencial, do tipo "ora a, ora b". A decisão se baseia na confiança num tipo de material de aquisição dos dados. No caso da crença, porém, a questão é apenas crer ou não em um dado único, quando já foi descartada outra proposta submetida à questão da confiança. Com os discursos de artigos especializados, a confiança não tem lugar (tem ainda menos nos artigos de vulgarização), já que, geralmente, se trata de fenômenos em processo de atestação. Esses discursos especializados se situam nos dois lados da estruturação tensiva do campo (analítico e sintético). Com efeito, além de apresentar brevemente a organização do tipo analítico (projeção posição-luz), eles participam de uma constituição sintética das unidades. Neste ponto de vista, além da dissimetria fundamental entre os eixos, o 
campo de ação das operações lógicas do conteúdo corresponde ao saber. Em outras palavras, trata-se do acesso ao conhecimento do objeto, contando com a avaliação anterior da sua existência, ou seja, da estabilização das suas formas. Neste âmbito, se houver concessões como operações de movimento dos conteúdos, elas funcionariam sobre bases tensivas diferentes, ora analítica, ora sintética. A concessão analítica possui como campo de ação o crer, enquanto a concessão sintética possui o saber.

Finalmente, poderíamos reconhecer tendências particulares dos discursos relativas às quantificações intensivas, sempre ficando no âmbito da distinção fundamental que acabamos de apresentar. Portanto, na perspectiva sintética, os discursos de vulgarização correspondem a uma estrutura tensiva ascendente $(+$ de +$)$ quando os discursos de artigos especializados participam de uma estrutura decadente $(+\mathrm{de}-$, ou $-\mathrm{de}+)$. Podem-se observar estes comportamentos nos dois exemplos da última seção: só o discurso de vulgarização usa a dinâmica concessiva (do tipo sintético) para qualificar os objetos. Em seguida, na perspectiva analítica, os discursos de revistas especializadas pertencem a uma estrutura tensiva decadente $(+\mathrm{de}-, \mathrm{ou}-\mathrm{de}+)$ quando os discursos de laboratório apresentam uma estrutura ascendente $(+$ de + ). Por isso os discursos de especialização são caracterizados por ausência de acontecimentos no sentido tensivo. Portanto, em ambos os casos, os discursos científicos escritos de especialização estão no mais baixo nível de quantificação intensiva, enquanto os dois demais discursos, nos níveis tensivos respectivos, convergem a uma dinâmica ascendente.

\section{AGRADECIMENTOS}

Queremos agradecer Bruna Paola Zerbinatti pelas suas leituras pacientes e suas correções do nosso português ainda imperfeito demais.

\section{REFERÊNCIAS}

ALLAMEL-RAFFIN, Catherine. La production et les fonctions des images en physique des matériaux e en astrophysique. (Tese de doutorado em epistemologia e história das ciências e técnicas). Strasbourg: Université Louis Pasteur, 2004. (4 volumes).

ARTERO, Arthur Felipe. A gigante também é binária. In: Scientific American Brasil. n. 43, dez. 2005, p.12-13.

COURBIN, F. COSMOGRAIL: the Cosmological Monitoring of Gravitational Lenses IX. Time delays and N-body realisations of the lens in HE 0435-1223". In: Astronomy \& Astrophysics. ESO, 2010. Disponível em: http://hdl.handle.net/2268/74288. Acesso em: 10 jul. 2012.

DONDERO, Maria Giulia. Sémiotique de l'image scientifique. Signata: PULg, n. 1, 2010, p. 111-175.

FONTANILlE, Jacques \& ZILBERBERG, Claude. Tensão e Significação. Tradução de Ivã Carlos Lopes, Luiz Tatit, Waldir Beividas. São Paulo: Humanitas/FFLCH-USP, 2001.

HÉBERT, Louis. Dispositifs pour l'analyse des texte et des images. Nouveaux Actes Sémiotiques. Introduction à la sémiotique appliquée. Limoges: Presses Universitaire de Limoges, 2009. 
CASA, Vol.10 n.1, julho de 2012

ZILBERBERG,Claude. Cheminements du poème. Baudelaire, Rimbaud, Valéry, Jouve. Limoges: Editions Lambert-Lucas, 2010.

Des formes de vie aux valeurs. Formes sémiotiques. Paris : Presses Universitaires de France, 2011.

Recebido em: 07/02/12

Aprovado em: 16/06/12 